\title{
PERAN, KEPENTINGAN STAKEHOLDER DAN DUKUNGAN KEBIJAKAN DALAM PENGEMBANGAN PARIWISATA BAHARI BERBASIS BUDAYA BAHARI DI MALAUMKARTA, KABUPATEN SORONG
}

\section{Role, Stakeholder Interest and Policy Support in the Development of A Marine Cultural Tourism in Malaumkarta, Sorong Regency}

\author{
*Umi Muawanah, Nendah Kurniasari, Permana Ari Soejarwo, dan Christina Yuliaty \\ Balai Besar Riset Sosial Ekonomi Kelautan dan Perikanan \\ Gedung BRSDM KP I Lt. 4, Jalan Pasir Putih Nomor 1 Ancol Timur, Jakarta Utara, Indonesia \\ Telp: (021) 64711583 Fax: 64700924
}

Diterima tanggal: 28 April 2020; Diterima setelah perbaikan: 22 Desember 2020;

Disetujui terbit: 28 Desember 2020

\begin{abstract}
ABSTRAK
Sejak 2018 pemerintah Kabupaten Sorong telah melakukan pengembangan pariwisata bahari berbasis budaya bahari di Malaumkarta. Pengembangan pariwisata merupakan prioritas pembangunan ekonomi di Kabupaten Sorong. Penelitian ini bertujuan untuk mengetahui peran dan minat pemangku kepentingan serta evaluasi dukungan terhadap peraturan di tingkat nasional dan lokal dalam pengembangan wisata bahari berbasis budaya bahari di Malaumkarta dengan mengunakan analisis hierarki proses (AHP) dan analisis konten. Penelitian dilakukan pada bulan Mei 2019 di Kabupaten Sorong. Hasil penelitian menunjukkan bahwa pengembangan wisata bahari di Malaumkarta merupakan bentuk partisipasi bersama dari pemerintah daerah dan masyarakat lokal diantaranya Dinas Pariwisata, Dinas Pekerjaan Umum, Loka Pengelolaan Sumber daya Pesisir dan Laut, Dinas Kelautan dan Perikanan, Bappeda Kabupaten Sorong serta Dewan "Adat" dan Lembaga Adat. Selain itu juga didukung penuh oleh dua peraturan daerah sangat mendukung wisata bahari yaitu Peraturan Daerah (Perda) Kabupaten Sorong No. 10 Tahun 2017 tentang acknowledgement dan perlindungan tradisi serta Keputusan Bupati No. 7 Tahun 2017 tentang hukum tradisional, kearifan lokal dalam pengelolaan dan konservasi sumber daya laut di Malaumkarta, Kabupaten Sorong. Penelitian ini menunjukkan bahwa stakeholder utama, stakeholder kunci dan stakeholder pendukung harus melakukan langkahlangkah strategis untuk peningkatan sinergitas peran yaitu dengan peningkatkan koordinasi antar SKPD, pembangunan fasilitas umum di lokasi wisata serta memberikan pelatihan dan pendampingan kepada masyarakat lokal untuk meningkatkan ketrampilan dan pengetahuan dalam mendukung pengembangan wisata bahari berbasis budaya bahari.
\end{abstract}

Kata Kunci: ekowisata bahari; Malaumkarta; Kabupaten Sorong; pariwisata bahari; hukum dan regulasi

\section{ABSTRACT}

The Development of marine tourism and maritime culture based tourism in Malaumkarta, Sorong was streghthened since 2018. Marine tourism has been a priority economic development in Sorong. This study aims to understand the role and interest from many Stakeholders in the further development of ecotourism in Sorong and to evaluate the support of laws and regulations in enhancing the ecotourism in Malaumkarta at national level and local level using Analysis of Hierarchy Proces (AHP). The research was carried out in May 2019 in the District of Sorong. The research shows that governance of marine tourism based on maritime culture in Malaumkarta is co-management tourism with strong supports from local government and local communities such as Office of Tourisme, office of Fisheries, Local Planning Bereu, and "Adat" council, and Village Adat Leaders. Two local regulation strongly support the marine tourism namely Peraturan Daerah (Perda) District of Sorong No. 10 year 2017 on Acknowledgement and Protection of Tradition and Bupati Decree No. 7 year 2017 on traditional laws and local wisdom in management and conservation of marine resources in Malaumkarta, District of Sorong. The study shows that main stakeholders, key stakeholders and supporting stakeholders need to have strategic programs and initiatives and to increase the roles sinergity among local government offices (SKPD), development of public faciltiy in tourism sites and provision of training and site assistance to local communiites enhanching their skills and knowledge in supporting the development of marine tourism based on maritime culture.

Keywords: marine ecotourism; Malaumkarta; Sorong Regency; marine tourism; law and regulation 


\section{PENDAHULUAN}

Wisata bahari merupakan aktivitas rekreasi yang meliputi perjalanan jauh dari suatu tempat tinggal menuju lingkungan laut, dimana lingkungan laut yaitu perairan yang dipengaruhi oleh pasang surut (Orams, 1999). Sementara itu menurut Djou (2013) menyatakan bahwa wisata bahari adalah sebuah bentuk wisata yang menggali keindahan lingkungan pantai dan laut sebagai daya tarik utama. Desain wisata bahari diutamakan pada view, keunikan alam, karakteristik ekosistem dan dipadukan dengan kekhasan seni budaya serta karakteristik masyarakat sebagai kekuatan dasar yang dimilikinya. Beberapa daerah yang telah berhasil mengembangkan wisata bahari adalah Yogyakarta dengan pesona Pantai Wediombo (Rif'an, 2008), Jakarta dengan pesona Pulau Tidung (Anggraeni, 2013), Bali dengan wisata bahari Pantai Sanur (Gautama \& Oka, 2011) serta wisata bahari Pantai Sikakap, Mentawai (Andriyani \& Husnita, 2012).

Salah satu wilayah yang saat ini sedang dikembangkan sebagai wisata bahari berbasis budaya bahari adalah Kampung Malaumkarta, Kabupaten Sorong, Papua Barat. Malaumkarta merupakan sebuah kampung yang terletak di distrik Makbon dengan jarak sekitar $\pm 48 \mathrm{~km}$ atau sekitar 1 sampai dengan 2 jam perjalanan dari Kota Sorong, yang dapat ditempuh menggunakan mobil, motor atau angkutan kota (Kurniasari et al., 2019). Secara topografi Kampung Malaumkarta terdiri dari gunung, lembah, lereng serta laut yang melingkar dan membentuk tanjung. Kampung Malaumkarta mempunyai sebuah pulau yang menarik sebagai andalan pariwisata yaitu Pulau Um. Pengembangan pulau tersebut sedang ditingkatkan melalui berbagai kegiatan wisata keindahan alam, budaya dan komoditas unggulan seperti dugong, penyu, dan burung camar. Selain keindahan alam dan ekosistemnya, keragamaan sosial budaya bahari merupakan salah satu modal kuat dalam pengembangan wisata bahari berbasis budaya di Kampung Malaumkarta. Kekhasan budaya dapat menjadi pengalaman tersendiri dari bagi wisatawan. Hal ini semakin memperkuat antara wisata bahari dan budaya sehingga memunculkan strategi baru untuk pariwisata (Putra, 2014). Penduduk Kabupaten Sorong secara sosial budaya terdiri atas penduduk asli dan pendatang. Menurut Kurniasari et al. (2019) penduduk asli di Kabupaten Sorong dapat dibagi ke dalam beberapa kelompok, yaitu: a)
Suku Moi adalah kelompok pemegang hak ulayat, terdiri dari suku: Klabra, Karon, Madik, Kebar, Keboro, dan Yaun, yang tersebar di distrik Fef, Abun, Sausapor, Moraid, Makbon, Aimas, Salawati, Seget, Segun, Beraur, Klamono, dan Sayosa; b) Suku Maybrat, terdiri dari suku: Meimere/Make, Meite, dan Meimaru, yang tersebar di distrik Aimas dan Salawati; c) Suku Inanwatan, terdiri dari suku: Mate Mani, Puragi, Oderau, Kaiso, dan Samaun, tersebar di distrik Aimas dan Salawati; d) Suku Tehit, terdiri dari suku: Sawiat, dan Ogit, tersebar di distrik Aimas dan Salawati; e) Suku Migran, yaitu berasal dari luar Provinsi Papua Barat, diantaranya dari: Jawa, Sunda, Batak, Makassar, Buton dan lain sebagainya.

Komposisi sosial budaya yang heterogen yang didukung oleh sumber daya manusia dan wilayah yang berbatasan dengan Kota Sorong akan menjadi potensi bagi pengembangan wisata berbasis budaya lokal. Terdapat beberapa karakter sosial dalam kehidupan bermasyarakat di Kampung Malaumkarta diantaranya memiliki orientasi kolektif dan rasa kekerabatan yang kuat. Masyarakat Malaumkarta juga memiliki tingkat ketaatan yang tinggi terhadap agama (Nasrani/ Gereja) dan menempatkan adat sebagai panglima dalam menyelesaikan konflik. Potensi wisata bahari dan aktivitas ekonomi kreatif di masyarakat merupakan hasil pengembangan produk budaya dan kearifan masyarakat lokal. Sebagai bagian dari produk budaya dan kearifan lokal bahari, wisata bahari dan aktivitas ekonomi kreatif dapat menjadi identitas dan ciri khas domestik pada masyarakat di suatu wilayah. Dari beragam budaya masyarakat lokal di Indonesia, budaya dan kearifan masyarakat Malaumkarta merupakan salah satu yang berpotensi untuk dikemas dan dikembangkan menjadi produk wisata bahari berbasis kearifan lokal. Aktivitas budaya bahari yang berbasis konservasi (pengelolaan sumber daya alam berkelanjutan), seperti egek/sasi dan kofok, merupakan salah satu budaya dan kearifan lokal bahari yang berkembang di Malaumkarta

Sistem tenurial Suku Moi merupakan hal yang penting untuk dibahas secara khusus dalam pengembangan ekonomi kreatif berbasis budaya bahari. Karena beberapa aktivitas kreatif dalam wisata bahari terkait erat dengan pemanfaatan ruang. Perlu ditekankan bahwa bagi masyarakat Suku Moi Hutan tanah leluhur adalah ibu kandung yang memberi kehidupan ${ }^{1}$.

\footnotetext{
${ }^{1}$ Tata Ruang dan Pertanahan. 2015. Ibu yang memberikan Kehidupan.http://www.tataruangpertanahan.com/kliping-1652-hutan-ibuyang-memberikan-kehidupan.html. Diunduh pada Tanggal 7 Oktober 2019
} 
Dukungan pemerintah dalam mengembangkan perpaduan antara wisata bahari dan wisata budaya bahari diprediksi akan memiliki daya tarik bagi wisatawan, baik wisatawan domestik maupun mancanegara. Kegiatan atraksi wisata bahari dan budaya bahari merupakan salah satu potensi objek wisata yang perlu dikembangkan oleh pemerintah daerah Kabupaten Sorong. Menimbang pentingnya pengembangan pariwisata bahari berbasis budaya bahari di Malaumkarta, maka diperlukan penelitian untuk menganalisis peran dan kepentingan stakeholder terkait di Kampung Malaumkarta dan bagaimana dukungan kebijakan nasional maupun kebijakan daerah dalam rangka pengembangan wisata bahari berbasis budaya bahari.

Penelitian yang dilakukan pada bulan Mei 2019 di Kampung Malumkarta, Kabupaten Sorong ini bertujuan untuk mengetahui peran dan minat pemangku kepentingan serta evaluasi dukungan terhadap peraturan di tingkat nasional dan lokal dalam pengembangan wisata bahari berbasis budaya bahari di Malaumkarta. Adapun tahapan pengumpulan data meliputi: 1) Melakukan identifikasi pemangku kepentingan terdiri dari stakeholders yang akan merasakan dampak atau memberikan dampak dari sebuah keputusan pemanfaatan sumber daya alam (Grimble \& Wellard, 1997). Dalam hal pengembangan wisata bahari berbasis budaya bahari, stakeholder yang relevan meliputi instansi pemerintah, lembaga konservasi, lembaga adat, pemerintah desa, warga kampong pesisir, kelompok wanita di desa pesisir, kelompok pemuda, penjual, pemilik dan penginapan. Namun dalam penelitian ini yang menjadi fokus analisa dan pembahasan adalah instansi pemerintah dan lembaga adat; dan 2) Melakukan pengumpulan data primer dan sekunder. Data dan informasi primer dikumpulkan melalui in depth interview dengan para pihak yang dipilih berdasarkan beberapa kriteria obyektif. Data dan informasi tersebut meliputi situasi yang terjadi dalam pengembangan wisata bahari berbasis budaya di Maluamkara serta para pihak yang terlibat beserta kepentingan, pengaruh, regulasi dan relasi informasi. Data sekunder dikumpulkan dari beberapa instansi yang terkait dengan penelitian diantaranya dinas pariwisata Kabupaten Sorong mengenai rencana induk pengembangan pariwisata, Bappeda Kabupaten Sororng mengenai masterplan pengembangan pariwisata di Kabupaten Sorong, BPS Kabupatan Sorong mengenai demografi dan sosial ekonomi kependudukan serta jurnal, dan laporan hasil penelitian yang relevan dengan tema penelitian.

Analisis data dilakukan dengan menggunakan Analisis Hirarki Proses (AHP) dan Content Analysis. AHP dilakukan dengan memberikan bobot pada masing masing faktor kemudian dilakukan perbandingan berpasangan antar faktor yang dikaji dengan mengunakan skala 1 sampai dengan 9. Skala 1 menunjukkan tingkat sama penting, sedangkan 9 menunjukkan tingkat mutlak lebih penting (Saaty, 2008). Skala AHP disajikan pada Tabel 1.

Selanjutnya langkah dalam melakukan tahapan AHP yaitu sebagai berikut:

- Menghitung normalized matrik yaitu proses menormalkan setiap faktor dengan cara membagi nilai per faktor dengan jumlah dari hasil seluruh faktor, dan hasil yang diperoleh merupakan nilai Eigen Vector.

- Setelah mendapatkan nilai Eigen vector kemudian menghitung nilai lamda maksimal (Amaks) dan Consistency Index (CI) sebelum menghitung Consistency Ratio (CR). Lamda maksimal dapat dihitung dengan menambahkan hasil perkalian nilai

Tabel 1. Skala Perbandingan Berpasangan AHP. Table 1. AHP Pairwise Comparison Scale.

\begin{tabular}{cl}
$\begin{array}{c}\text { Intensitas Kepentingan/ } \\
\text { Intensity of Interest }\end{array}$ & \multicolumn{1}{c}{$\begin{array}{c}\text { Definisi/ } \\
\text { Definition }\end{array}$} \\
\hline 1 & Sama lebih penting/The same is more important \\
3 & Sedikit lebih Penting/ A little more important \\
5 & Jelas lebih penting/ Obvious/y more important \\
9 & Mutlak lebih Penting/ Absolute is more important \\
$2,4,6$ dan 8 & $\begin{array}{l}\text { Nilai-nilai diantara dua pertimbangan yang berdekatan/ } \\
\text { The values between the two considerations are close together }\end{array}$ \\
\hline
\end{tabular}

Sumber: Saaty (2008)/Source: Saaty (2008). 
perbandingan dengan nilai hasil eigen vector untuk semua faktor. Apabila $\mathrm{Cl}$ bernilai nol, maka matrik perbandingan tersebut konsisten. Batas ketidakkonsistenan (inconsistency) yang telah ditetapkan oleh Thomas L. Saaty ditentukan dengan menggunakan rasio konsistensi (CR), yaitu perbandingan indeks konsistensi dengan nilai random indeks (RI) (Tabel 2). Dengan demikian, rasio konsistensi dapat dirumuskan sebagai berikut:

$$
\mathrm{CR}=\mathrm{CI} / \mathrm{RI}
$$

Dimana/Where:

$$
\begin{aligned}
& \mathrm{CR}=\text { Consistency Ratio } \\
& \mathrm{CI}=\text { Consistency index } \\
& \mathrm{RI}=\text { Random Index }
\end{aligned}
$$

Lebih lanjut content analysis dilakukan untuk menganalisis regulasi dan kebijakan nasional mengenai pengembangan wisata bahari yang diperoleh dari Kementerian Kelautan dan Perikanan serta Kementerian Pariwisata. Adapun regulasi dan kebijakan lokal diperoleh dari Biro Hukum Kabupaten Sorong. Berdasarkan analisis tersebut dapat menguraikan isi komunikasi yang jelas secara objektif dan sistematis serta memberikan interpretasi (Suprayogo, 2001). Regulasi dan kebijakan ini juga dianalasis secara analisis kualitatif untuk mengetahui dukungan dan hambatan dari regulasi yang ada dalam pengembangan wisata bahari berbasis budaya bahari.

\section{PERAN DAN RELASI ANTAR STAKEHOLDERS}

Pengembangan kegiatan wisata bahari dengan budaya bahari tidak terlepas dari peran aktif stakeholder baik dari sektor pemerintah, swasta maupun masyarakat. Menurut Latupapua (2015) diterangkan bahwa stakeholders dapat dibagi menjadi tiga kelompok yaitu stakeholder utama, stakeholder kunci dan stakeholder pendukung. stakeholder utama merupakan entitas yang dapat terkena dampak langsung baik yang bersifat positif maupun negatif dari suatu program yang diinisiasi. Oleh karena itu, stakeholder utama ini harus ikut serta penuh dalam tahapan proses kegiatan. stakeholder kunci merupakan aktor yang mempunyai kewenangan secara resmi dalam pengambilan keputusan, dalam hal ini adalah yang bertanggung jawab pada pengembangan wisata bahari berbasis budaya di Maluamkara Kabupaten Sorong, Papua Barat. Stakeholder pendukung merupakan aktor yang tidak memiliki kepentingan langsung terhadap program yang sedang dikerjakan, akan tetapi memliki sisi kepedulian yang besar dalam tahapan pengembangan program tersebut. Stakeholder pendukung ini dapat bertindak sebagai fasilitator program yang sedang dikerjakan dan berpengaruh terhadap pengambilan keputusan. Amalyah, Hamid, \& Hakim (2016) menyebutkan bahwa stakeholders wisata bahari berupa pemerintah, pelaku pariwisata dan masyarakat lokal. Masyarakat lokal dapat berpartisipasi dalam mendukung pengembangan wisata bahari dengan cara menjaga dan terlibat dalam usaha pariwisata (Dalimunthe, 2007). Amanah \& Utami (2006) menyebutkan bahwa dalam pengembangan wisata bahari diperlukan adanya koordinasi antara nelayan, pemerintah lokal, Lembaga Swadaya Masyarakat, dan private sector untuk meningkatkan performance dari pelayanannya.

Berdasarkan hasil survei lapangan diperoleh beberapa stakeholder yang mempunyai kepentingan dalam mendukung kesiapan kelembagaan dalam meningkatkan nilai tambah wisata bahari berbasis budaya bahari di Kabupaten Sorong. Beberapa stakeholder tersebut adalah: Dinas Pariwisata, Lembaga Adat, Dinas Kelautan dan Perikanan, Loka Pengelolaan Sumber daya Pesisir dan Laut (LPSPL) Sorong, Dinas Pekerjaan Umum, Bappeda, dan Dewan Adat Desa. Secara singkat,

Tabel 2. Indeks Random (RI).

Table 2. Random Index (RI).

\begin{tabular}{cccccc}
\hline $\begin{array}{l}\text { Ordo matrik/ } \\
\text { Matrix order }\end{array}$ & RIIRI & $\begin{array}{l}\text { Ordo matrik/ } \\
\text { Matrix order }\end{array}$ & RI/RI & $\begin{array}{c}\text { Ordo matrik/ } \\
\text { Matrix order }\end{array}$ & RI/RI \\
\hline 1 & 0 & 6 & 1.24 & 11 & 1.51 \\
2 & 0 & 7 & 1.32 & 12 & 1.48 \\
3 & 0.58 & 8 & 1.41 & 13 & 1.56 \\
4 & 0.9 & 9 & 1.45 & 14 & 1.57 \\
5 & 1.12 & 10 & 1.49 & 15 & 1.59 \\
\hline
\end{tabular}

Sumber: Saaty (2008)/Source: Saaty (2008). 
LPSPL melakukan pengelolaan dan pendampingan dalam kawasan egeg/sasi di Malaumkarta sebagai salah satu opsi wisata bahari berbasis alam dan budaya bahari, Dinas Pariwisata memberikan program-program pengembangan wisata bahari di Malaumkarta seperti pembangunan pantai Malaumkarta, lembaga adat dan dewan adat beserta kelompok pemuda merupakan penggerak konservasi di wilayah egeg dan wisata bahari di Pantai Malaukarta, Dinas Pekerjaan Umum berperan dalam pembangunan sarana prasarana penunjang wisata bahari, dan Bappeda sebagai koordinator semua SKPD dalam membangun wisata bahari di Sorong. Hasil yang diperoleh dari pendekatan analytical hierarchy process (AHP) untuk mengetahui peran dan relasi stakeholder dalam pengembangan wisata bahari dapat digambarkan dari perbandingan berpasangan terhadap 7 (tujuh) stakeholder yang diperlihatkan pada Tabel 3.

Tabel 3 menunjukkan bahwa Dinas Pariwisata merupakan stakeholder yang menempati urutan pertama dalam mendukung pengembangan budaya bahari untuk meningkatkan nilai tambah wisata bahari di Malaumkarta, Kabupaten Sorong, Papua Barat, baik dari sisi promosi maupun regulasi, peran ini salah satu tugas dan fungsi utama Dinas Pariwisata. Urutan kedua Dinas Pekerjaan Umum, yang mempunyai peran penting dalam pengembangan sektor pariwisata terutama dalam pembangunan fisik guna medukung akses menuju ke lokasi wisata maupun pembangunan fasilitas umum di lokasi wisata. Peran penting ketiga yaitu dilakukan oleh Dewan Adat Desa, dukungan nyata dalam pengembangan wisata bahari di Malaumkarta salah satunya yaitu dengan penyadaran masyarakat dalam menjaga kelestarian sumberdaya alam dengan menjaga telur-telur penyu. Loka Pengelolaan Sumber daya Pesisir dan Laut (LPSPL) berada pada urutan keempat, peran LPSPL salah satunya melakukan kegiatan konservasi di Pulau Um dan peningkatan kapasitas masyarakat adat setempat dalam hal konservasi lingkungan. Dinas Kelautan dan Perikanan (DKP) berada pada urutan kelima, peran penting DKP yaitu mendukung masyarakat pesisir di lokasi wisata untuk meningkatkan ketrampilan dalam pengolahan hasil perikanan. Urutan keenam Lembaga adat, peran penting lembaga ini yaitu menjaga kearifan lokal masyarakat adat dalam pengembangan wisata bahari. Urutan ketujuh yaitu Bappeda, yang berperan dalam melakukan koordinasiantar sektor serta memastikan tercapainya target utama pembangunan wisata bahari Kabupaten Sorong. Adapun penjabaran dari masing-masing peran stakeholder berdasarkan hasil perhitungan AHP sebagai berikut:

\section{a) Dinas Pariwisata}

Merupakan instansi yang mempunyai peran utama dalam pengembangan wisata bahari bersama-sama SKPD lain seperti Dinas Pekerjaan

Tabel 3. Hasil Perbandingan Berpasangan Antara 7 (tujuh) Stakeholders.

Table 3. The Results of a Pairwise Comparison Between 7 (seven) Stakeholders.

\begin{tabular}{|c|c|c|c|c|c|c|c|c|c|}
\hline $\begin{array}{l}\text { Matriks/ } \\
\text { Matrix }\end{array}$ & $\begin{array}{l}\text { DISPARI } \\
\text { District } \\
\text { office of } \\
\text { tourism }\end{array}$ & $\begin{array}{c}\text { LPSPLI } \\
\text { Local } \\
\text { conservation } \\
\text { office of } \\
\text { MMAF } \\
\end{array}$ & $\begin{array}{c}\text { Dinas KPI } \\
\text { District } \\
\text { office of } \\
\text { marine and } \\
\text { fisheries }\end{array}$ & $\begin{array}{c}\text { Lembaga } \\
\text { Adat/ } \\
\text { Local adat } \\
\text { Institution }\end{array}$ & $\begin{array}{l}\text { Bappedal } \\
\text { Local } \\
\text { planning } \\
\text { office }\end{array}$ & $\begin{array}{c}\text { Dewan Adat } \\
\text { Desal } \\
\text { Village } \\
\text { indigenous } \\
\text { board }\end{array}$ & $\begin{array}{l}\text { Dinas PU/ } \\
\text { Office of } \\
\text { public } \\
\text { works }\end{array}$ & $\begin{array}{l}\text { Bobot/ } \\
\text { Weight }\end{array}$ & $\begin{array}{l}\text { Peringkat/ } \\
\text { Ranking }\end{array}$ \\
\hline $\begin{array}{l}\text { DISPAR/ District } \\
\text { office of tourism }\end{array}$ & 1 & 2.222 & 3.297 & 1.509 & 2.646 & 1.448 & 2.064 & 0.225 & 1 \\
\hline $\begin{array}{l}\text { LPSPL/ Local } \\
\text { conservation } \\
\text { office of MMAF }\end{array}$ & 0.450 & 1 & 4.596 & 2.515 & 2.446 & 0.390 & 0.376 & 0.142 & 4 \\
\hline $\begin{array}{l}\text { Dinas KP/ } \\
\text { District office } \\
\text { of marine and } \\
\text { fisheries }\end{array}$ & 0.303 & 0.218 & 1 & 2.527 & 1.388 & 2.653 & 0.228 & 0.121 & 5 \\
\hline $\begin{array}{l}\text { Lembaga Adat/ } \\
\text { Local adat } \\
\text { institution }\end{array}$ & 0.663 & 0.398 & 0.396 & 1 & 1.481 & 0.291 & 0.498 & 0.077 & 6 \\
\hline $\begin{array}{l}\text { Bappeda/ Local } \\
\text { planning office }\end{array}$ & 0.378 & 0.409 & 0.721 & 0.675 & 1 & 0.288 & 0.340 & 0.058 & 7 \\
\hline $\begin{array}{l}\text { Dewan Adat } \\
\text { Desa/ Village } \\
\text { indigenous } \\
\text { board }\end{array}$ & 0.691 & 2.567 & 0.377 & 3.436 & 3.467 & 1 & 0.785 & 0.176 & 3 \\
\hline $\begin{array}{l}\text { PU/ Office of } \\
\text { public works }\end{array}$ & 0.485 & 2.660 & 4.380 & 2.009 & 2.944 & 1.275 & 1 & 0.200 & 2 \\
\hline Jumlah/Total & 3.969 & 9.473 & 14.766 & 13.671 & 15.372 & 7.345 & 5.290 & 1 & $C R=0.101$ \\
\hline
\end{tabular}


Umum, Dinas Kelautan dan Perikanan, Bappeda, Dewanadatdan Pemerintah Kampung Malaumkarta. Dilihat dari berbagai sisi, dinas pariwisata merupakan stakeholder yang paling bertanggung jawab dalam sektor pengembangan pariwisata dalam hal ini wisata bahari. Pengembangan wisata bahari yang dilakukan tidak hanya dari sisi promosi melainkan juga dari sisi regulasi. Promosi berperan penting dalam memperkenalkan kekayaan alam dan budaya bahari yang khas sehingga dapat menjadi daya tarik wisatawan untuk berkunjung. Widiatedja (2011) menyatakan bahwa promosi memegang peran vital dalam proses pencitraan dan pemasaran suatu produk. Seindah, sebagus, dan seandal apapun kualitas suatu produk akan menjadi tidak berarti apabila tidak didukung oleh upaya promosi yang kreatif dan inovatif.

Selain program-program promosi mengenai tempat-tempat wisata, budaya dan identifikasi potensi wisata baru, Dinas Pariwisata Kabupaten Sorong juga harus aktif dalam pengembangan kapasitas komunitas kampung di tempat wisata. Hal ini dapat memberikan dua keuntungan sekaligus yaitu adanya partisipasi masyarakat dan rasa memiliki kawasan pariwisata tersebut sehingga masyarakat bersedia untuk ambil bagian dalam pemeliharaan lingkungan. Di samping itu masyarakat pun dapat merasakan manfaat ekonomi dari kegiatan wisata dalam kehidupan sehari-hari sehingga diharapkan akan tercipta prinsip pariwisata berkelanjutan.

Adanya komponen budaya dan partisipasi masyarakat lokal dalam pengembangan wisata bahari di Kampung Malaumkarta menunjukkan bahwa implementasi prinsip pariwisata berkelanjutan telah diwujudkan. Keberlanjutan budaya menggambarkan adanya tingkat kontrol kehidupan terhadap kesesuaian dengan budaya dan nilai-nilai yang dapat memperkuat identitas suatu masyarakat/komunitas (McKercher, 2003).

\section{b) Dinas Pekerjaan Umum}

Mengemban amanah dalam pembangunan infrastruktur dan sarana prasarana untuk penguatan wisata bahari berbasis budaya bahari di Malaumkarta. Pembangunan homestay dan bungalow, pembangunan infrastruktur jembatan, jalan dari ibukota Kabupaten Sorong ke Malaumkarta, pemecah gelombang di Pulau Um serta pembangunan sarana prasarana umum berupa tempat parkir dan toilet. Hal ini sesuai dengan pernyataan Ardianti (2016) bahwa Dinas
Pekerjaan Umum merupakan salah satu instansi yang ikut ambil bagian dalam pengembangan wisata bahari yang berkoordinasi dengan Bappeda dalam bentuk rencana pembangunan jalan dan jembatan menuju objek wisata di pantai tersebut serta fasilatas umum lainnya di lokasi wisata sehingga diharapkan menimbulkan rasa nyaman bagi wisatawan.

\section{c) Dewan Adat Kampung Malaumkarta}

Merupakan komunitas pokok pelaksana dan yang paling merasakan dampak baik positif maupun negatif dari kegiatan wisata bahari di Pantai Malaumkarta. Dampak paling nyata adalah mulai dikenalnya pesisir Malaumkarta dan banyaknya wisatawan lokal yang datang untuk menikmati pantai maupun menikmati pulau Um dari pantai Malaumkarta. Hal tersebut telah memberikan dampak ekonomi bagi masyarakat walaupun masih relatif kecil.

Komponen dari wisatawan yang dapat dirasakan dampaknya oleh masyarakat berasal biaya parkir, pengeluaran makan dan minum serta ongkos sewa perahu menuju Pulau Um. Hal penting yang menjanjikan dalam pengelolaan wisata bahari berbasis budaya bahari adalah keinginan warga kampung Malaumkarta untuk peningkatan kapasitas dan keterampilan warganya guna menjadi pelaku aktif dalam mendukung aktivitas pariwisata tersebut. Harapan ini disampaikan oleh wakil kelompok pemuda, kepala kampung dan anggota dewan adat Kampung Malaumkarta.

Kepala Kampung Malaumkarta selalu menyatakan bahwa seluruh warga siap mendukung implementasi Perda destinasi wisata di Malumkarta. Selain itu, masyarakat siap mendukung peningkatan kenyamanan dan keamanan para wisatawan di Malaumkarta guna mendukung wisata bahari berbasis budaya bahari jika dikembangkan dalam waktu dekat. Seluruh jajaran tokoh kampung juga cukup terbuka dalam melakukan eksplorasi potensi budaya sebagai atraksi wisata.

Salah satu potensi budaya yang dapat dieksplorasi sebagai atraksi budaya yaitu upacara meminta ijin dari nenek moyang yang dinamakan "benvie" dapat menjadi paket wisata yang sangat menarik bagi wisatawan. Selain itu community right yang kuat terhadap sumber daya pesisir dan daratan di Malaumkarta merupakan hal positif dalam pengembangan wisata bahari. 
Sepanjang pesisir Malaumkarta adalah hak ulayat darikeluarga Suku Moiyang digunakan secara bertanggung jawab dalam menenuhi kebutuhan hidup sehari-hari. Saat ini para tokoh Kampung Malaumkarta telah membuat draft Peraturan Kampung Malaumkarta. Peraturan ini akan mengatur tentang pungutan yang diperbolehkan sesuai kesepakatan pemilik wilayah pesisir pantai dengan segenap komponen masyarakat kampung dan kesepakatan penggunaan dana yang terkumpul untuk kepentingan komunitas. Selain itu, peraturan desa yang telah disusun ini diharapkan menjadi pemicu kesadaran masyarakat bahwa pelaku jasa layanan wisata untuk para wisatawan berasal dari masyarakat Malaumkarta sendiri, bukan berasal dari pendatang. Sehingga manfaat ekonomi akan lebih banyak dirasakan oleh Kampung Malaumkarta.

\section{Peraturan Kampung Malaumkarta juga akan mengatur kegiatan-kegiatan wisata berbasis konservasi seperti jumlah kunjungan ke Pulau Um, hal-hal yang diperbolehkan dan yang tidak diperbolehkan di Pulau Um. Hal ini mempertimbangkan banyaknya telur-telur penyu di Pulau Um. Wisatawan juga tidak diperbolehkan untuk menginjak tempat-tempat tertentu yang digunakan sebagai demplot (demontration plot) telur penyu di sepanjang Pantai Um. Kegiatan wisata yang ramah lingkungan juga diterapkan seperti membawa kembali botol minuman plastik yang dibawa ke Pulau Um untuk di recycle, hal ini diatur atau ditetapkan dalam Peraturan Kampung tersebut.}

Peraturan Kampung juga mengatur wisatawan yang datang ke Pulau Um pada malam hari agar menggunakan lampu warna merah sehingga tidak mengganggu bayi-bayi penyu dan penyu-penyu yang akan mendarat maupun pergi ke laut. Menurut Bennett \& Dearden (2014) menyatakan bahwa keberhasilan daerah konservasi dipengaruhi oleh partisipasi aktif masyarakat lokal. Maka dari itu pemahaman masyarakat mengenai konservasi dan pemanfaatannya sangat diperlukan. Masyarakat lokal merupakan pihak yang sangat berhubungan dengan kegiatan wisata bahari di Malaumkarta dan dan peran untuk mengarahkan dalam kegiatan wisata bahari tersebut.

\section{d) Loka Pengelolaan Sumber daya Pesisir dan Laut (LPSPL) Sorong}

Unit Pelayanan Teknis (UPT) Direktorat Jenderal Pengelolaan Ruang Laut - Kementerian
Kelautan dan Perikanan ini salah satunya bertanggung jawab dalam menjaga kelestarian penyu di Pulau Um dan melakukan pembinaan konservasi lingkungan kepada masyarakat adat Moi di Kampung Malaumkarta.

Berdasarkan hasil survei lapang diketahui bahwa LPSPL Sorong dan masyarakat Kampung Malaumkarta mempunyai koordinasi dan kerjasama yang sangat kuat dalam programprogram konservasi maupun pengembangan kapasitas masyarakat tentang konservasi dan pentingnya melindungi penyu-penyu di Pulau Um. Pada awalnya, penyu merupakan salah satu hewan yang dikonsumsi di Malaumkarta. Namun demikian saat ini kebiasan tersebut sudah ditinggalkan berkat kesepakatan antara warga dengan tokoh-tokoh masyarakat Malaumkarta tentang pentingnya menjaga kelestarian penyu. Populasi penyu merupakan daya tarik wisatawan sehingga diprediksi mampu memberikan manfaat ekonomi kepada masyarakat Malaumkarta.

Peran serta masyarakat dalam pengelolaan sumber daya kelautan dan perikanan merupakan modal yang sangat baik dalam mewujudkan keberlanjutan sumber daya kelautan dan perikanan Pulau Um. Masyarakat pesisir merupakan aktor yang berhubungan langsung dengan penerima manfaat dari keberlanjutan tersebut.

\section{e) Dinas Kelautan dan Perikanan (DKP) Kabupaten Sorong}

Berperan dalam pengelolaan sumber daya perikanan dan keluatan di Pantai Malaumkarta dan Pulau Um. DKP Kabupaten Sorong dan LPSPL Sorong mempunyai beberapa kesamaan misi dalam hal pengelolaan sumber daya Kelautan dan Perikanan. DKP Kabupaten Sorong dalam pengembangan wisata bahari berbasis budaya bahari terus berupaya dalam melakukan program yang lebih aktif dari sisi peningkatan kapasitas masyarakat pesisir dan nelayan di lokasi-lokasi wisata bahari seperti Pantai Malaumkarta. Salah satu program yang menjadi sasaran yaitu dalam pengolahan hasil perikanan.

\section{f) Lembaga Adat meliputi Ikatan Keluarga Malaumkarta (IKM) dan Mala Moi.}

Tugas lembaga adat antara lain menjaga kearifan lokal masyarakat Moi yang merupakan pemilik wilayah kepala burung di Pulau Papua dan menjaga nilai-nilai tradisional yang diwarisi dari 
para leluhur. Dua hal tersebut, apabila diekplorasi, dijaga, dikemas serta dipraktekkan akan mampu menjadi daya tarik wisata. Masyarakat dan komunitas Moi di Kabupaten Sorong terutama di Kampung Malaumkarta siap menjaga keamanan dan kenyamanan para wisatawan lokal maupun dari provinsi lain.

Lembaga adat Moi sangat mendukung bahwa masyarakat menjadi bagian penting dalam kelestarian ekosistem baik ekosistem hutan maupun laut yang merupakan hak marga-marga suku Moi. Hal ini sesuai dengan pernyataan (Shaleh, 2016) bahwa lembaga adat merupakan salah satu faktor kekuatan dalam mengelola wisata bahari melalui sistem pengelolaan, sistem pengembangan, menjaga kelestarian lingkungan, dan mengembangkan adat budaya lokal.

\section{g) Bappeda Kabupaten Sorong}

Bertugas untuk melakukan koordinasi antar sektor dalam memastikan tercapainya target utama pembangunan Kabupaten Sorong yaitu pengembangan wisata di Kabupaten Sorong, dimana saat ini andalan wisata pesisir Kabupaten Sorong adalah Kampung Malaumkarta. Selain itu, Bappeda Kabupaten Sorong juga bertugas untuk melakukan perencanaan teknis dan sinergitas program antar SKPD Kabupaten Sorong.

\section{DUKUNGAN REGULASI DAN KEBIJAKAN DALAM PENGEMBANGAN WISATA BAHARI BERBASIS BUDAYA BAHARI}

Tataran perundangan-undangan nasional dan peraturan yang mengatur wisata bahari meliputi Undang-Undang, Peraturan Pemerintah, Peraturan Presiden dan Peraturan Menteri Kelautan dan Perikanan. Perundangan dan regulasi tersebut terutama dalam hal perijinan pembuatan sarana dan prasarana wisata bahari di pesisir dan kegiatan wisata bahari di kawasan konservasi. Peraturan yang berasal dari pemerintah pusat mencakup UU No. 27 Tahun 2007, UU No. 45 Tahun 2009, UU No. 31 Tahun 2014, UU No. 26 Tahun 2007, UU No. 10 Tahun 2009, Perpres No. 122 Tahun 2010, Perpres No. 34 Tahun 2019, PP No, 60 Tahun 2007. PP No. 36 Tahun 2010, PP No. 32 Tahun 2019, PP No. 24 Tahun 2018, Permen KP No. 28 Tahun 2014, Permen KP No. 61 Tahun 2018, dan Permen KP No. 8 Tahun 2019.

Pada Undang-Undang No. 27 Tahun 2007 Jo UU No. 1 Tahun 2014 mengatur pengelolaan wilayah pesisir. Dalam hal ini, maka pemanfaatan ruang dan ekosistem pesisir yang digunakan untuk wisata bahari perlu mendapatkan izin menggunakan dan mengelola kawasan atau sumber daya. Izin dapat diberikan kepada kelompok perorangan dengan ketentuan-ketentuan tertentu dalam jangka waktu tertentu. Kawasan konservasi dan budaya bahari egek di Malaumkarta menjadi kawasan konserbasi Penyu yang dikelaola oleh UPT KKP yaitu LPSPL Sorong beserta penggiat konservasi dari kelompok pemuda dan dewan adat desa Malaumkarta.

Lebih lanjut pada Undang Undang No. 30 Tahun 2009 tentang kepariwisataan mengatur mengenai jenis-jenis wisata, asas penyelenggaran, dan kawasan strategis. UU ini juga mengakui bahwa pentingnya budaya dalam aspek pariwisata terutama pariwisata berbasis pengalaman tradisi. Hal ini menjadi dasar penting dalam pengembangan budaya bahari sebagai basis wisata bahari dan mendapatkan prioritas program dari pemerintah pusat seperti Kementrian Pariwisata dan Ekonomi Kreatif (Kemenparkraf).

Adapun peraturan daerah mengenai pengembangan wisata meliputi Perda Sorong Tahun 2015, Perda Kabupaten Sorong No. 10 Tahun 2017, dan Peraturan Bupati Sorong No. 7 Tahun 2017 tentang Hukum Adat dan Kearifan Lokal dalam Pengelolan dan Perlindungan Sumber daya laut di Kampung Malaumkarta. Kabupaten Sorong telah mempunyai rancangan Peraturan Daerah tentang rencana induk pengembangan pariwisata Kabupaten Sorong tahun 2015-2025. Strategi pembangunan dan pengembangan pariwisata dengan pusat-pusat destinasi pariwisata meliputi peningkatan fungsi kawasan objek daerah tujuan wisata sebagai pusat pengembangan kegiatan wisata dan peningkatan interaksi antar objek dan atraksi wisata satu sama lain dalam meningkatkan efisiensi pengembangan pariwisata. Strategi pengembangan kelengkapan prasarana wilayah meliputi transportasi, energi listrik, telekomunikasi, sumber daya air bersih dalam mendukung pengembangan pariwisata. Adapun pusat kegiatan wisata bahari di Kabupaten Sorong meliputi Pantai Makbon, Pantai dan perairan Yeflio, Pantai dan gugusan pulau-pulau Katapop, Perairan selancar Walio, Pantai Pulau Um, Perairan selancar Kampung Moraid, Resort pulau-pulau Mayamuk, Pantai dan peraiaran Malaumkarta, Pantai Teluk Dorey, dan Perairan pancing Seget - Sele - Makbon. Penyelenggaraan usaha dan pemanfaatan ruang kawasan peruntukan kepariwisataan dan kerja sama antar 
lintas sektor/antar daerah bidang pariwisata, harus dikoordinasikan dengan Bidang Penanaman Modal Daerah dan Bidang Fisik Prasarana Bappeda Kabupaten Sorong.

Selanjutnya berdasarkan Peraturan Daerah Kabupaten Sorong No. 10 Tahun 2017 tentang Pengakuan dan Perlindungan Masyarakat Hukum Adat Moi di Kabupaten Sorong, Pemerintah Daerah Kabupaten Sorong memberikan Pengakuan dan perlindungan hak Masyarakat Hukum Adat Moi. Perda Kabupaten Sorong tersebut mengatur aspek kunci pengakuan masyarakat hukum adat dengan tujuan perlindungan, kedudukan masyarakat hukum adat Moi, kelembagaan masyarakat, cakupan wilayah masyarakat adat, tugas/wewenang masyarakat adat Moi.

Wilayah adat Masyarakat hukum adat Moi disebut Malamoi. Wilayah ini dimiliki oleh 8 sub suku yaitu Kelom, Sigin, Abun Taat, Abun Jii, Klabra, Saikhma, Lemas. Dan Maya. Menurut Peraturan Bupati Sorong No 10 Tahun 2017 Tentang Pengakuan dan Perlindungan Masyarakat Hukum Adat Moi di Kabupaten Sorong, pembagian wilayah asministratif setiap sub suku adalah sebagai berikut:

a. Wilayah Adat Kelim terdapat dalam wilayah administratif Distrik Mega, Distrik Klaso, Distrik Selemkai, Distrik Saingkeduk, Distrik Makbon, Distrik Klaili, Distrik Aimas, Distrik Sorong, Distrik Mariat, Distrik Mayamuk, Distrik Klamono, Distrik Klasafet, dan Distrik Sayosa;

b. Wilayah Adat Sigin terdapat dalam wilayah administratif Distrik Segun, Distrik Sigin, dan Distrik Salawati.

c. Wilayah Adat Lemas terdapat dalam wilayah administratif Distrik Seget

d. Wilayah Adat Maya terdapat di dalam wilayah administratif Distrik Salawati Selatan, dan Salawati Tengah.

e. Wilayah Adat Abun Taa terdapat dalam wilayah administratif Distrik Maudus dan Distrik Sunook

f. Wilayah Abun Jii terdapat dalam wilayah asministratif Distrik Saingkeduk

g. Wilayah Saikhma terdapat dalam wilayah administratif Distrik Sayosa Tomur dan Wemak;

h. Wilayah Klabra terdapat dalam wilayah administratif Distrik Beraur, Distrik Klabon, Distrik Bangun, Distrik Botain, Distrik Hobart, Didstrik Konfir, Distrik Klawak, dan Distrik Buk.
Pada Pasal 12 dalam peraturan yang sama disebutkan bahwa penguasaan dan pemanfaatan tanah ulayat yang berada di wilayah masyarakat Hukum Adat Moi secara komunal atau milik bersama dan lahan kelola pribadi, yang pembagiannya berdasarkan tata guna lahan peliputi Tanah Adar, Hutan Adat, dan kawasan pesisir,laut dan pulau adat. Tanah adat ini tidak boleh dirubah status penguasaan dan pemilikan lahannya. Sementara lahan kelola pribadi didasarkan tata guna lahannya yang meliputi lahan pemukiman, pekarangan dan kebun.

Sementara itu, Peraturan Bupati Sorong No. 7 tahun 2017 tentang Hukum Adat dan Kearifan Lokal dalam pengelolaan dan perlindungan sumber daya laut di Malaumkarta, diantaranya bahwa peran masyarakat adat dalam mengelola sumber daya, mengelola biota yang dilindungi dan tata cara pelaksanaan sanksi bagi pelanggar aturan pengelolaan berbasis hak adat tersebut. Peran aktif masyarakat adat dalam pengelolaan sumber daya alam meliputi pengumpulan data dan informasi sebagai acuan awal, perencanaan dan pengelolaan, serta melakukan pengawasan. Peraturan Bupati tersebut menyebutkan beberapa jenis biota yang dilindungi oleh masyarakat hukum adat di wilayah pesisir dan pulau-pulau kecil yaitu kima, dugong, penyu (telur dan tukik), parimanta, cetacean, lumba-lumba, dan hiu paus, sedangkan biota laut yang yang dilindungi berdasarkan konservasi secara traditional ('Egeg”) meliputi teripang, lola dan lobster.

\section{INTEGRASI PERAN STAKEHOLDER DAN REGULASI PENGEMBANGAN WISATA BAHARI BERBASIS BUDAYA BAHARI}

Berdasarkan tugas dan fungsi stakeholders dalam pembangunan wisata bahari berbasis budaya bahari di Malaumkarta, Kabupaten Sorong, Papua Barat terdiri atas stakeholder utama diantaranya Dinas Pariwisata dan Dinas Pekerjaan Umum; stakeholder kunci yaitu Loka Pengelolaan Sumber daya Pesisir dan Laut (LPSPL) dan Dinas Kelautan dan Perikanan; stakeholder pendukung yaitu Bappeda, Dewan Adat dan Lembaga Adat. Salah satu faktor utama keberhasilan partisipasi stakeholder dalam kegiatan pengembangan pariwisata berbasis budaya bahari adalah komunikasi dan koordinasi antara stakeholder baik utama, kunci dan pendukung yang harus berjalan optimal serta mempunyai target waktu. Hal ini sesuai pernyataan Jupir (2013) bahwa kurang optimalnya komunikasi dan koordinasi antar 
stakeholder menyebabkan pariwisata berbasis kearifan lokal belum berkontribusi secara optimal bagi pemerintah, swasta dan masyarakat dari sisi ekonomi. Seluruh stakeholder harus memegang prinsip pengelolaan wisata bahari berbasis budaya bahari (pribumi) dengan mengutamakan kedaulatan masyarakat lokal, kelestarian sumber daya alam dan budaya yang merupakan tujuan utama dalam kegiatan pariwisata tersebut (Sinclair, 2003).

Pada tataran perundangan-undangan Nasional dan peraturan yang mengatur wisata bahari meliputi Undang-Undang, Peraturan Pemerintah, Peraturan Presiden dan Peraturan Menteri Kelautan dan Perikanan, terutama perizinan pembuatan sarana dan prasarana wisata bahari di pesisir dan kegiatan wisata bahari di kawasan konservasi, seperti Undang-Undang No. 27 Tahun 2007 Jo UU No. 1 Tahun 2014, UU No. 30 Tahun 2009. Adapun peraturan daerah pengembangan wisata di Sorong meliputi Perda Sorong Tahun 2015, Perda Kab. Sorong No. 10 Tahun 2017, dan Peraturan Bupati Sorong No. 7 Tahun 2017 tentang Hukum Adat dan Kearifan Lokal dalam Pengelolan dan Perlindungan Sumberdaya laut di Kampung Malaumkarta. Dukungan regulasi dan kebijakan terkait dengan pengembangan wisata bahari di Malaumkarta dalam skala nasional maupun lokal sudah tergolong lengkap dari segi pariwisata, adat istiadat, kearifan lokal dan konservasi. Dalam penyelenggaraanya, peraturan-peraturan tersebut perlu dikoordinasikan dengan Bidang Penanaman Modal Daerah dan Bidang Fisik Prasarana serta Bappeda Kabupaten Sorong.

Interaksi antara stakeholder pengembangan wisata bahari berbasis budaya bahari cukup kuat, terutama peran kelompok pemuda dan dewan adat desa di Malaumkarta. Hal ini cukup menjanjikan dalam pengembangan ekonomi lokal dan keberlanjutan sumber daya alam/konservasi serta budaya bahari sebagai komoditas dan jasa utama dalam pengembangan wisata bahari di Malaumkarta. Cuffin and Jubbin (2003) menemukan sebaliknya bahwa pengembangan wisata bahari di Marocco dan Tunisia dimana peran pemerintah sangat dominan dan penduduk lokal berperan belum optimal.

\section{SINTESA KEBIJAKAN}

Interaksi antara stakeholder pengembangan wisata bahari berbasis budaya bahari cukup kuat, terutama peran kelompok pemuda dan dewan adat desa di Malaumkarta. Hal ini cukup menjanjikan dalam pengembangan ekonomi lokal dan keberlanjutan sumber daya alam/konservasi serta budaya bahari sebagai komoditas dan jasa utama dalam pengembangan wisata bahari di Malaumkarta. Cuffin and Jubbin (2003) menemukan sebaliknya bahwa pengembangan wisata bahari di Marocco dan Tunisia dimana peran pemerintah sangat dominan dan penduduk lokal berperan belum optimal. Peningkatan peran masyarakat lokal dalam pengembangan wisata Bahari di Malaumkarta dapat ditingkatkan melalui dukurang regulasi tingkat desa seperti Peraturan Desa dimana keterlibatan penduduk dalam berbagai aktifitas ekonomi kegiatan wisata bahari dapat diinisiasi oleh penduduk desa sendiri, pemanfaatan dana desa untuk pengembangan keterampilan dalam ekonomi kreatif wisata bahari seperti literasi internet, ide kreatif pemasaran/ permasaran digital dan lain lain.

\section{IMPLIKASI KEBIJAKAN}

Dalam rangka menuju pengembangan wisata bahari berbasis budaya bahari yang telah didukung oleh peraturan pusat dan daerah, maka pemerintah perlu melakukan langkah-langkah strategis untuk peningkatan sinergitas peran Stakeholder melalui beberapa integrasi program: 1) Bappeda Kabupaten Sorong berperan aktif melakukan koordinasi antar SKPD guna memantau kemajuan/progres pengembangan wisata bahari di Kampung Malaumkarta setiap triwulan sekali. Forum Percepatan Pariwisata merupakan salah satu opsi integrasi sinergitas antara berbagai stakeholder wisata bahari di Malaumkarta; 2) Dewan adat dan lembaga adat melakukan inventarisasi budaya bahari dan menyiapkan event-event pilihan serta memberikan jadwal terkait kegiatan budaya bahari yang akan dijadikan sebagai objek wisata untuk dikoordinasikan dengan Dinas Pariwisata; 3) Dinas Pariwisata dan Dinas Pemberdayaan Perempuan memberikan pelatihan dan pendampingan kepada masyarakat lokal meliputi: pelatihan pemandu wisata (guide), pelatihan manajemen guest house (rumah penginapan), pelatihan teknis kewirausahaan dalam bidang ekonomi kreatif dan membuat show room untuk hasil ekonomi kreatif masyarakat lokal; 4) Dinas Pekerjaan Umum melakukan identifikasi dan pembangunan fasilitas umum di lokasi wisata bahari di Malaumkarta untuk meningkatkan kenyamanan wisatawan; 5) Dinas Kelautan 
dan perikanan memberikan pelatihan dan pendampingan dalam peningkatan nilai tambah dan daya saing produk perikanan sebagai salah satu bentuk ekonomi kreatif bagi masyarakat lokal; dan 6) LPSPL Sorong perlu melakukan monitoring dan evaluasi terhadap programprogram konservasi yang telah dilaksanakan di Kampung Malaumkarta, serta lebih intensif dalam melakukan sosialisasi dan pendampingan dalam kegiatan konservasi agar semakin bertambah masyarakat lokal yang mempunyai pengetahuan terhadap kegiatan konservasi tersebut.

\section{UCAPAN TERIMA KASIH}

Terima Kasih ditujukan kepada Balai Besar Riset Sosial Ekonomi Kelautan dan Perikanan yang telah mendanai penelitian ini. Kami ucapkan terima kasih kepada Loka Pengelolaan Sumber daya Pesisir dan Laut (LPSPL) Sorong, Dewan Adat Malaumkarta, Dinas Pariwisata, WWF, serta Politeknik Kelautan dan Perikanan Sorong yang telah membantu dalam hal pengumpulan data selama penelitian dilaksanakan.

\section{PERNYATAAN KONTRIBUSI PENULIS}

Umi Muawanah dan Permana Ari Soedjarwo sebagai Kontributor Utama dan Nendah Kurniasari dan Christina Yuliati sebagai kontributor Anggota.

\section{DAFTAR PUSTAKA}

Andriyani, I., \& Husnita, L. (2012). Perubahan Sosial Ekonomi Masyarakat Pasca Pengembangan Wisata Bahari Di Kepulauan Sikakap, Kabupaten Mentawai. Jurnal IImu Sosial Mamangan, 1(2), 95-101. doi: 10.22202/ mamangan.1355.

Anggraeni, A. A. (2013). Analisis dampak ekonomi wisata bahari terhadap pendapatan masyarakat di pulau tidung. Reka Loka, Vol 1(1). Retrieved from http://ejurnal.itenas.ac.id.

Amalyah, R., Hamid, D., \& Hakim, L. (2016). Peran Stakeholder Pariwisata Dalam Pengembangan Pulau Samalona Sebagai Destinasi Wisata Bahari. Jurnal Administrasi Bisnis, Vol 37(1), 158-163. Retrieved from http://administrasibisnis. studentjournal.ub.ac.id/.

Amanah, S., \& Utami, H. N. (2006). Perilaku Nelayan Dalam Pengelolaan Wisata Bahari di Kawasan Pantai Lovina, Buleleng, Bali. Jurnal Penyuluhan, 2(2). doi: 10.25015/penyuluhan. v2i2.2185.
Ardianti. (2016). Kebijakan Dinas Pariwisata Dalam Pengelolaan Wisata Bahari Pantai Batu Kasah Di Desa Cemaga Tengah Kecamatan Bunguran Selatan Kabupaten Natuna. Laporan Thesis Universitas Maritim Raja Ali Haji Tanjungpinang.

Bennett, N.J., \& Dearden, P. (2014). Why local people do not support conservation: Community perceptions of marine protected area livelihood impacts, governance and management in Thailand. Marine Policy, 44, 107-116. doi: 10.1016/j. marpol.2013.08.017.

Bibin, M., Vitner, Y., \& Imran, Z. (2018). Analysis of Stakeholder in the development of Labombo Beach sustainable town in Palopo City. Masyarakat, Kebudayaan dan Politik 31 (1):62-71. doi: 10.20473/mkp.V31I12018.62-71.

Caffyn, Alison, \& Jobbins, Guy. (2003). Governance Capacity and Stakeholder Interactions in the Development and Management of Coastal Tourism: Examples from Morocco and Tunisia. Journal of Sustainable Tourism, 11(2-3), 224-245.

Dalimunthe, N. (2007). Partisipasi Masyarakat dalam Pengembangan Potensi Wisata Bahari Pantai Cermin Kabupaten Serdang Bedagai (Master's thesis).

Djou, J. A. G. (2013). Pengembangan 24 Destinasi Wisata Bahari Kabupaten Ende. Jurnal Kawistara, 3 (1). doi: 10.22146/kawistara.3958.

Dwyer, L. (2017). Coastal and marine tourism in the Indian Ocean rim Studies, Vol 1 (1) ISSN 1694-3317: Challenges and opportunities. Journal of Indian Ocean Rim Studies, 1(1), 38-55. Retrieved from https://www.researchgate.net/.

Gautama, I. A. G. O., \& Oka, G. A. G. (2011). Evaluasi Perkembangan Wisata Bahari di Pantai Sanur. Prog. Pascasarjana, Universitas Udayana, Denpasar. Retrieved from https://ojs.unud.ac.id.

Grimble, R., \& Wellard, K. (1997). Stakeholder methodologies in natural resource management: a review of principles, contexts, experiences and opportunities. Agricultural systems, 55(2), 173-193. doi: 10.1016/S0308-521X(97)00006-1.

Jupir, M. M. (2013). Implementasi kebijakan pariwisata berbasis kearifan lokal (studi di Kabupaten Manggarai Barat). Journal of Indonesian Tourism and Development Studies, Vol 1(1), 28. Retrieved from https://scholar.google.com/.

Kurniasari, N., Muawanah, U., Zulham, A., Yuliaty, C., Trianti, R., Soejarwo, P. A., \& Koeshendrajana, S. (2019). Model Penerapan Kegiatan Ekonomi Kreatif Berbasis Budaya Bahari dan Kearifan Lokal Dalam Penciptaan Nilai Tambah Wisata Bahari. Laporan Teknis T. A 2019 Balai Besar Riset Sosial Ekonomi Kelautan dan Perikanan. Jakarta. 
Latupapua, Y., Th. (2015). Implementasi peran stakeholder dalam pengembangan ekowisata di Taman Nasional Manusela (TNM) di Kabupaten Maluku Tengah. Jurnal Agroforestri, X (1), ISSN: 1907-7556.

McKercher, B. (2003). Sustainable Tourism DevelopmentGuiding Principles For Planning And Management. International Seminar on Sustainable tourism Development Bishkek, Kyrgystan

Orams, M. (1999). Marine tourism: development, impacts and management. Retrieved from https://books. google.co.id.

Putra, I. N. D. (2014). Bali: between cultural and marine tourism. Jurnal Kajian Bali (Journal of Bali Studies), Vol 4(1). Retrieved from https:// ojs. unud.ac.id.

Rif'an, A. A. (2018). Daya Tarik Wisata Pantai Wediombo Sebagai Alternatif Wisata Bahari Di Daerah Istimewa Yogyakarta. Jurnal Geografi, 10(1), 63-73. doi: 10.24114/jg.v10i1.7955.

Saaty, T. L. (2008). Decision making with the analytic hierarchy process. International journal of services sciences, Vol 1(1), 83-98. Retrieved from https://scholar.google.com/.

Shaleh, T. M. (2016). Peran Lembaga Adat Dalam Pengelolaan Wisata Bahari (Studi Kasus Di pantai pandawa Desa Adat Kutuh Badung-Bali). Prosiding Seminar Nasional Tahunan ke-V Hasil Penelitian Perikanan dan Kelautan.

Sinclair, D. (2003). Developing indigenous tourism: challenges for the Guianas. International Journal of Contemporary Hospitality Management, Vol 15(3), 140-146. Retrieved from https://emerald.com/.

Suprayogo, I. (2001) Metodologi Penelitian SosialAgama, Bandung: Remaja Rosdakarya, 2001

Widiatedja, I.G.P. (2011). Kebijakan Liberalisasi Pariwisata: Konstruksi Konsep, Ragam Masalah dan Alternatif Solusi. Cetakan Pertama. Udayana University Press. Bali. 